\title{
Microrrestos de vegetales cultivados y silvestres en fragmentos cerámicos. Primeras evidencias en el Centro Occidente argentino
}

\section{(1) Cristina Prieto-Olavarría", Horacio Chiavazza" y M. Gabriela Musaubach"***}

Recibido: 15 de marzo de 2018 Aceptado: 12 de julio de 2018

Palabras clave

Centro occidente argentino Arqueobotánica Microrrestos vegetales Cerámica Maíz

Algarrobo

\section{Cultivated and wild plant micro-remains from ceramic fragments. First evidences from West-central Argentina}

\section{Keywords}

West-central Argentina Archaeobotany Plant micro-remains Pottery

Maize

Algarrobo

\footnotetext{
* Instituto Argentino de Nivología, Glaciología y Ciencias Ambientales (IANIGLA), Universidad Nacional de Cuyo (UNCu)-CONICET/Instituto de Arqueología y Etnología (IAyE), Facultad de Filosofía y Letras, Universidad Nacional de Cuyo (UNCu). Av. Ruiz Leal s/n, Parque General San Martín (CP 5500), Mendoza, Argentina. E-mail: cprieto@mendoza-conicet.gob.ar

** Instituto de Arqueología y Etnología (IAyE), Facultad de Filosofía y Letras, Universidad Nacional de Cuyo (UNCu). Museo del Área Fundacional, Secretaría de Cultura de la Municipalidad de Mendoza. Centro Universitario, Parque General San Martín (CP M5502JMA), Mendoza, Argentina. E-mail: hchiavazza@gmail.com *** Facultad de Humanidades y Ciencias Sociales, Universidad Nacional de Jujuy (UNJu). Otero 262 (CP 460o), San Salvador de Jujuy, Jujuy, Argentina. E-mail: gabrielamusa@gmail.com
} 


\section{Introducción}

El centro occidente argentino fue el límite meridional de la agricultura (Gil et al., 2014a; Lagiglia, 1980). Los productos agrícolas más tempranos hallados en este área se recuperaron en contextos datados hace aproximadamente 2.000 años AP (Bárcena, 2001; Gambier, 2000; Gil, Tykot, Neme y Shelnut, 2006). Se propuso que al inicio de la segunda mitad del Holoceno tardío, hace unos 2000 años, hubo cambios en la economía regional y macro regional que cristalizaron en un proceso de intensificación económica que involucró la ampliación de la base de subsistencia a partir de la intensificación en el uso de los recursos, incluyendo la incorporación de plantas domésticas (Neme, 2007).

Este trabajo se centra en dos sitios del norte de la provincia de Mendoza, ubicados entre los $32^{\circ} \mathrm{y} \operatorname{los} 33^{\circ} \mathrm{S}$. Junto al centro provincial, este sector posee el mayor registro de cultígenos y fuertes señales isotópicas en muestras humanas que indican mediano y alto consumo de maíz (Gil, Giardina, Neme y Ugan, 2014b). Atendiendo a la necesidad de afinar el conocimiento sobre el consumo de plantas, cultivadas y silvestres, en este trabajo se analiza por primera vez en la región, la evidencia de microrrestos vegetales recuperados en residuos de uso y consumo de fragmentos cerámicos. Se seleccionaron tiestos de dos sitios ubicados en diferentes ambientes: Rincón de Los Helados, en la Puna de precordillera (Chiavazza, 1995), y Memorial de La Bandera, uno de los sitios con alfarería y con casas semi-subterráneas más tempranos del piedemonte (Chiavazza, 2015).

El estudio de los microrrestos vegetales de interés arqueológico, tales como granos de almidón, fitolitos y polen, permite analizar el uso de las plantas para el estudio de la alimentación prehispánica así como también estudiar otros tipos de relaciones entre la flora y las sociedades en el pasado. Los datos paleodietarios pueden inferirse a través de diferentes vías analíticas: microrrestos presentes en el tártaro dental, sedimento de la zona abdominal de entierros humanos, isótopos estables del carbono y nitrógeno y residuos macroscópicos de uso depositados en las paredes de contenedores cerámicos, metodología que se aplica en este trabajo (Giovannetti, Lema, Bartoli y Capparelli, 2008; Piperno, 2006; Zucol, Brea y Passeggi, 2008, entre otros).

\section{Marco ambiental y estrategias de subsistencia durante el Holoceno tardío}

El centro occidente argentino se extiende entre $\operatorname{los} 32^{\circ}$ y los $37^{\circ} \mathrm{S}$, sobre la Diagonal Árida Sudamericana. Esta área es mediterránea y posee un clima árido a semiárido, con un promedio de precipitaciones anual alrededor de $250 \mathrm{~mm}$. Posee tres grandes unidades geobioclimáticas: las montañas al Este; las planicies y depresiones en el centro y Este, y las mesetas y volcanes de la Payunia. Las montañas tienen una elevación media de $3.500 \mathrm{~m}$ s.n.m, con picos entre los 5.000 y $6.000 \mathrm{~m}$ s.n.m., mientras que las llanuras tienen escasa pendiente y alturas entre los 600 y $400 \mathrm{~m}$ s.n.m. (Abraham, 2000). Las montañas y la Payunia están expuestas a la acción de los anticiclones del Pacífico: la primera incluye la Provincia fitogeográfica Andina por encima de $4.000 \mathrm{~m}$ y la Provincia Puneña entre 2.200 y $4.500 \mathrm{~m}$; la Payunia se inserta en la Provincia fitogeográfica Patagónica. El piedemonte y la llanura están expuestos a la acción de los anticiclones del Atlántico y se integran en la Provincia de Monte, caracterizada por vegetación xerófila (Larrea sp.) y un estrato arbóreo de Prosopis flexuosa (Roig, Martínez Carretero y Méndez, 2000).

Investigaciones recientes plantean que entre los 1500 y 2000 años AP las sociedades de la región comenzaron un proceso de regionalización y cambios económicos como consecuencia de la intensificación económica regional que permitió completar su adaptación a las condiciones ambientales locales (Neme, 2007). El alcance habría sido macrorregional, incluyendo la zona central de Chile y la provincia San Juan (Falabella y 
Stehberg, 1989; Gambier, 2000; Neme y Gil, 2008). En el sur mendocino la intensificación se manifestó en la colonización de nuevos hábitats, por ejemplo los marginales de La Payunia y la alta cordillera. Además, implicó la ampliación de la base de subsistencia a partir de la intensificación en el uso de los recursos animales y vegetales, incluyendo la incorporación de plantas domésticas. Estas transformaciones estuvieron acompañadas por numerosas estrategias relacionadas con cambios en el patrón de asentamiento, la organización tecnológica, la reducción de la movilidad y la ampliación de las redes de intercambio. La causa habría sido el aumento en la presión demográfica regional y el consecuente impacto de las poblaciones humanas sobre la estructura regional de recursos (Neme, 2007). Este desbalance habría generado la necesidad de cambiar las estrategias de explotación y tecnología, conduciendo a la sobreexplotación del paisaje y la disminución de los recursos altamente ranqueados (p. ej. el guanaco), por lo cual la subsistencia se orientó a la explotación de alimentos con bajos rendimientos calóricos y mayores costos de procesamiento, estimulando la adopción de plantas domésticas como el maíz (Gil, 2006; Neme, 2007). El proceso de intensificación también se planteó a partir de los ca. 1500 años AP en la precordillera del norte de Mendoza (valle de Potrerillos) donde las poblaciones practicaron la agricultura, habitaron casas semisubterráneas, explotaron recursos silvestres y redujeron su movilidad (Cortegoso, 2006).

\section{Vegetales cultivados pre-europeos en el centro occidente argentino}

Hasta la llegada de los españoles, el centro occidente argentino fue el límite meridional oriental de la dispersión agrícola (Gil et al., 2014a, 2014b; Lagiglia, 1980). Se postuló que este límite se fijó en el río Atuel hace 2.000 años, donde pequeñas familias de agricultores incipientes se asentaron de forma semipermanente, consumieron productos silvestres y no portaron cerámica (Lagiglia, 2001). En base a información etnográfica y arqueológica, el área se dividió en dos subáreas culturales separadas por una zona buffer en la Norpatagonia Mendocina-Neuquina: la septentrional en el Centro Oeste Argentino con registro de cultígenos en los contextos arqueológicos y la meridional que no incluía plantas domésticas y se caracterizaba por una economía cazadora-recolectora (Lagiglia, 1980). Los estudios históricos plantearon que a la llegada de los españoles la región estaba ocupada por dos grupos étnicos: el Huarpe agricultor del norte y el Puelche cazador-recolector del sur (Prieto, [1983] 2000).

La evidencia de plantas cultivadas en el centro occidente argentino se basó en el hallazgo de macrorrestos (Bárcena, 2001; Gambier, 2000; Gil et al., 2006), especialmente el maíz, recuperado en el $80 \%$ de los sitios con cultígenos (Gil et al., 2014b). Un total de 32 sitios arqueológicos presentan restos de vegetales cultivados pre-europeos, correspondientes a nueve taxa: Lagenaria sp., Zea mays, Cucurbitacea, Cucurbita ssp., Cucurbita maxima, Cucurbita moschata, Phaseolus ssp., Phaseolus vulgaris, Chenopodium quinoa y Capsicum sp. (Gil et al., 2014b). En el norte de Mendoza se recuperaron restos en sitios del piedemonte, de la planicie noreste, de la precordillera y de las pampas altas de precordillera (Mafferra, 2010), aunque solo en estos dos últimos ambientes se registraron plantas cultivadas y silvestres en contextos pre-europeos.

Hasta la década de 1990 se postuló que la presencia de cultígenos evidenciaba la práctica agrícola y el proceso de sedentarización de las poblaciones locales (Bárcena, 2001; García, 1992). Actualmente se replantea la importancia y valor de las plantas cultivadas dentro de distintas estrategias de subsistencia: se cuestiona la falsa dicotomía caza-recolección/agricultura, se plantea la relación no directa entre la presencia de plantas cultivadas y la práctica agrícola de las poblaciones que las portaron y se postula una trayectoria no lineal entre la incorporación de cultígenos, el cambio de sistema económico y su mayor importancia en la dieta a través del tiempo (Gil, 2006; Gil, Neme y Tykot, 2010). En el sur mendocino, los cultígenos hallados en contextos de hace 2000 
años pudieron tener un rol simbólico, mientras que los registrados en La Payunia hace 1000 años habrían sido obtenidos por intercambio con poblaciones vecinas y su función se habría asociado a la subsistencia en baja intensidad (Gil, 2006).

Respecto a las plantas silvestres, se propuso su relevancia en la dieta de las poblaciones locales desde tiempos prehispánicos hasta los históricos (Rusconi, 1961). La evidencia arqueológica indica la presencia de macrorrestos de cactus, algarrobo, chañar y molle entre otros, en asociación a plantas cultivadas desde hace más de 2000 años (Bárcena, Roig y Roig, 1985; Durán y García, 1989; García, 1988; Sacchero y García, 1988). Cabe destacar que el algarrobo (Prosopis ssp.) es un árbol abundante en las tierras bajas (Roig et al., 2000).

Los resultados del análisis isotópico de muestras humanas recuperadas entre los $30^{\circ} \mathrm{y}$ los $36^{\circ} \mathrm{S}$ y de la evidencia de macrorrestos permitieron proponer que la agricultura no fue un proceso generalizado en el territorio ni progresivo en el tiempo que reemplazó al sistema cazador-recolector (Gil et al., 2008). La variación temporal y espacial de los datos isotópicos y arqueobotánicos (Gil et al., 2006; Mafferra, 2010; Ots, Oliszewski, y García Llorca, 2011), sugiere que el consumo de plantas cultivadas fue dinámico durante el Holoceno tardío. El maíz fue significativo en la dieta humana de la zona entre los $30^{\circ}$ y los $33^{\circ} \mathrm{S}$ durante los últimos 1.000 años (Gil et al., 2014a). Por su parte, los estudios arqueobotánicos del periodo de contacto hispano-indígena y colonial temprano muestran que el maíz no tuvo un rol significativo (Chiavazza y Mafferra, 2007).

\section{Materiales y métodos}

\section{Sitios y muestras cerámicas}

El sitio Rincón de los Helados (RH) es un abrigo rocoso ubicado en la pampa de Canota a $3.000 \mathrm{~m}$ s.n.m, la cual posee cordones de sierras en el sector occidental mientras que en el oriental nacen quebradas que conectan con el piedemonte. RH se localiza en la cabecera de una de estas quebradas y presenta la sucesión de usos continuos desde hace aproximadamente 2000 años, con una mayor densidad de artefactos durante los últimos 600 - 500 años. Posee ocupaciones posiblemente vinculadas a un uso continuo orientadas a la talla de artefactos líticos, especialmente de rocas disponibles en precordillera, y actividades relacionadas con la caza y el procesamiento de animales in situ, especialmente guanacos (Chiavazza, 1995).

El sitio Memorial de la Bandera (MB) es un sitio a cielo abierto ubicado en el piedemonte de Mendoza a $700 \mathrm{~m}$ s.n.m. Está ubicado en el Centro Cívico de la ciudad de Mendoza, entre los 400 y $450 \mathrm{~cm}$ de profundidad de la superficie. Se detectaron rasgos vinculados con actividades segregadas como espacios habitacionales correspondientes a casas semi-subterráneas, hornillos y fogones. Se recuperó material cerámico, lítico, arqueobotánico, arqueofaunístico y sedimentario que está siendo analizado. Las dataciones radiocarbónicas obtenidas del Rasgo 3, correspondiente a una casa semisubterránea, indican ocupaciones tempranas alrededor de los 2000 años AP (Tabla 1) (Chiavazza, 2015; Chiavazza et al., 2018).

La selección de los fragmentos para el análisis de microrrestos adheridos a las superficies se hizo considerando la presencia macroscópica de residuos en las paredes internas y/o externas (Musaubach, 2017; Skibo, 2015). Estos corresponden a adherencias cuyas características indican el origen orgánico y tienen apariencia untuosa y quemada (Musaubach y Berón, 2017). Se evaluaron macroscópicamente los tiestos de ambos sitios y se seleccionaron y tomaron muestras de cuatro ejemplares con residuos carbonizados (Tabla 2). En los casos en que la muestra de residuos era abundante, se realizó un 


\begin{tabular}{|l|l|l|l|l|}
\hline $\begin{array}{l}\text { Fragmento } \\
\text { cerámico }\end{array}$ & Sitio arqueológico & Contexto & $\begin{array}{l}\text { Parte de la vasija y } \\
\text { forma }\end{array}$ & Datación o ubicación temporal \\
\hline RH C6 -6- 13 & $\begin{array}{l}\text { Rincón de Los } \\
\text { Helados }\end{array}$ & $\begin{array}{l}\text { Techo del } \\
\text { componente Vl. } \\
\text { Contexto doméstico }\end{array}$ & $\begin{array}{l}\text { Unión borde-cuello. } \\
\text { Forma restringida }\end{array}$ & $\begin{array}{l}\text { Techo del Componente IV (Chiavazza, } \\
\text { 1995). Por asociación contextual se ubica } \\
\text { entre los 8oo y los 1500 años AP. }\end{array}$ \\
\hline MB 13 & $\begin{array}{l}\text { Memorial de La } \\
\text { Bandera }\end{array}$ & Rasgo 1 & $\begin{array}{l}\text { Cuerpo. Forma } \\
\text { indeterminada }\end{array}$ & - \\
\hline MB 18 & $\begin{array}{l}\text { Memorial de La } \\
\text { Bandera }\end{array}$ & Rasgo 3 Casa semi- & $\begin{array}{l}\text { Cuerpo. Forma } \\
\text { indeterminada }\end{array}$ & $\begin{array}{l}\text { Base del Rasgo 3: carbón, 2100 } \pm \text { 80 (Latyr } \\
\text { LP3195). }\end{array}$ \\
MB 20 & $\begin{array}{l}\text { Memorial de La } \\
\text { Bandera }\end{array}$ & $\begin{array}{l}\text { Cuerpo. Forma } \\
\text { indeterminada }\end{array}$ & $\begin{array}{l}\text { Techo del Rasgo 3: carbón, 1910 } \pm 80 \text { (Latyr } \\
\text { LP30) (Chiavazza et al., 2018) }\end{array}$ \\
\hline
\end{tabular}

Tabla 1. Fragmentos cerámicos analizados de Rincón de Los Helados (RH) y Memorial de la Bandera (MB).

\begin{tabular}{|l|c|c|c|c|c|c|c|c|c|}
\hline Fragmento Cerámico & \multicolumn{3}{|c|}{ RH C6-6- 13 } & MB13 & \multicolumn{2}{c|}{ MB18 } & \multicolumn{3}{c|}{ MB20 } \\
\hline $\begin{array}{l}\text { Tipo de microrresto vegetal / } \\
\text { Muestras }\end{array}$ & 1 & 2 & 2 bis & 3 & 4 & 4 bis & 5 & 5 bis & 6 \\
\hline Grano almidón Prosopis sp. & 0 & 0 & 0 & 0 & 0 & 0 & 1 & 0 & 0 \\
Grano almidón Zea mays & 0 & 2 & 0 & 0 & 0 & 0 & 1 & 0 & 0 \\
Fitolito de sílice & 0 & 3 & 1 & 0 & 0 & 0 & 3 & 0 & 0 \\
Esporomorfo & 0 & 0 & 0 & 0 & 0 & 0 & 1 & 0 & 0 \\
Fragmentos de hongos & 0 & 0 & 0 & 0 & 0 & 0 & 1 & 0 & 0 \\
\hline
\end{tabular}

Tabla 2. Resultados del análisis de microrrestos vegetales de fragmentos cerámicos de $R H$ y MB.

duplicado que se indica con la palabra "bis". La manipulación de los fragmentos se realizó evitando su contaminación durante las labores de campo y acondicionamiento.

Se tomaron tres muestras de la cara interna del fragmento de $\mathrm{RH}$ : muestra 1, muestra 2 y muestra 2bis. De MB se analizaron tres tiestos: del tiesto MB13 se obtuvo la muestra 3 de la cara interna del fragmento; de MB18 se tomaron las muestras 4 y 4 bis de la cara interna del fragmento; del MB20 se tomaron las muestras 5, 5bis y 6 obtenidas de la cara externa del tiesto (Tabla 1; Figura 1).

\section{Métodos}

La extracción de los residuos macroscópicos de uso adheridos a la cerámica se realizó siguiendo un protocolo de extracción múltiple para recuperar la totalidad de los microfósiles preservados (Musaubach, 2014, 2017). El análisis múltiple de microfósiles maximiza la extracción combinada, la observación e integración de la mayor variabilidad posible de tipos de microvestigios por sobre el enfoque especializado sobre uno solo de ellos. A tal fin, se emplearon criterios metodológicos propuestos originalmente por Babot (2007) para el análisis de granos de almidón de contextos arqueológicos pero que puede ser extendida a cualquier tipo de estudio de microfósiles de interés arqueológico y es en este sentido que los aplicamos en esta investigación. Las etapas incluyeron la recuperación o extracción, montaje, observación y registro de las muestras arqueológicas. Luego se realizó la interpretación de los resultados en términos de la asignación taxonómica y anatómica de los microfósiles recuperados y de la identificación de procesos tafonómicos de origen antrópico o natural involucrados. En esta etapa es importante la implementación de controles para la evaluación de variables de supervivencia y contaminación. 


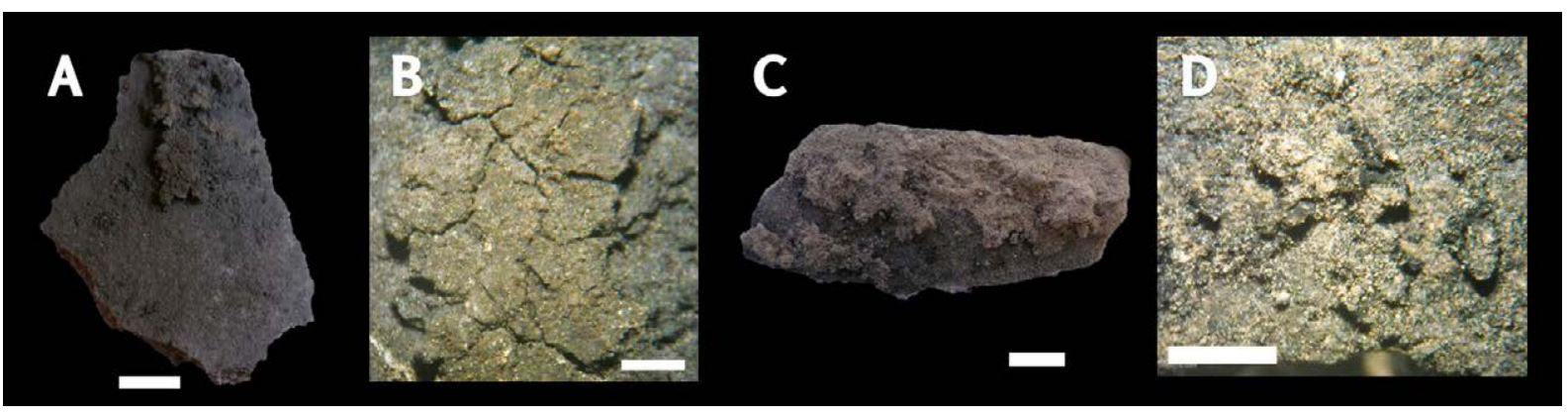

Figura 1. Fragmentos seleccionados con presencia de microrrestos vegetales adheridos a la superficie de los sitios Rincón de Los Helados (RH) y Memorial de la Bandera (MB). A) tiesto RH (6-6-13 y B) detalle del sector muestreado; C) tiesto MB2o y D) detalle del sector muestreado (D).

Los fragmentos fueron fotografiados y se registraron y evaluaron las siguientes variables: cara de depósito (interna-externa), coloración (crema-ocre-negra), textura (resinosa-granulosa-polvorienta), espesor y cantidad (porcentaje de superficie que cubre sobre la superficie del tiesto) y presencia de clastos o precipitados (carbonatos-otros).

El análisis de los residuos se hizo en escala macroscópica y microscópica: 1) observación in situ con lupa binocular; 2) limpieza con agua destilada para extraer el sedimento superficial adherido; 3) extracción con una punta de metal de dos a tres muestras directamente sobre el portaobjetos: la primera muestra corresponde a los primeros milímetros de espesor de los residuos y la segunda son los residuos ubicados inmediatamente por debajo de la anterior; 4) el 20\% de la muestra se usó para el análisis y el $80 \%$ de los residuos recuperados se conservó como testigo en un recipiente estéril; 5) observación y conteo usando un microscopio Leica con luz polarizada a 400 aumentos. Las fotomicrografías se tomaron con una cámara digital Nikon Coolplix.

El análisis microscópico se orientó a la identificación de microfósiles de interés arqueológico, principalmente gránulos de almidón, silicofitolitos y restos de tejido vegetal deshidratado (Musaubach, 2017).

\section{Resultados}

A partir de la observación al microscopio se constató la presencia de microrrestos vegetales en las muestras 2, 2bis y 5 . En las muestras 2 y 2 bis de $\mathrm{RH}$, se observaron granos de almidón de Zea mays: granos poliédricos o irregulares con cuatro a cinco lados que presentan facetas de presión, los tamaños oscilan entre 2 y $10 \mu \mathrm{m}$ (Korstanje y Babot, 2007), presentan hilo central en forma de $\mathrm{V}$ o líneal, la posición de la cruz de Malta es central con cuatro brazos regulares visibles (Musaubach, Plos y Babot, 2013) (Tabla 2) (Figura 2E y F). También se observaron: dos fitolitos de sílice que corresponden a tricomas (Figura $2 \mathrm{~A}$ y C), uno del tipo elongado sin asignación taxonómica (Figura 2B) y el otro de tipo saddle. Este último morfotipo es común en gramíneas de la subfamilia Chloridoideae $\mathrm{C}_{4}$ (Figura 2D).

En la muestra 5 se observó un grano de almidón de Zea mays (Figura 2M) y un grano de almidón de Prosopis sp. (Figura 2L). Este último es de morfología regular con superficies redondeadas o facetadas y su tamaño no supera los $10 \mu \mathrm{m}$, presenta el hilo en posición central, su birrefringencia es alta y la cruz de Malta es central de cuatro brazos cortos, finos y rectos (Giovannetti et al., 2008). También se registró un esporomorfo y restos de hongos (Tabla 2; Figura 2). 

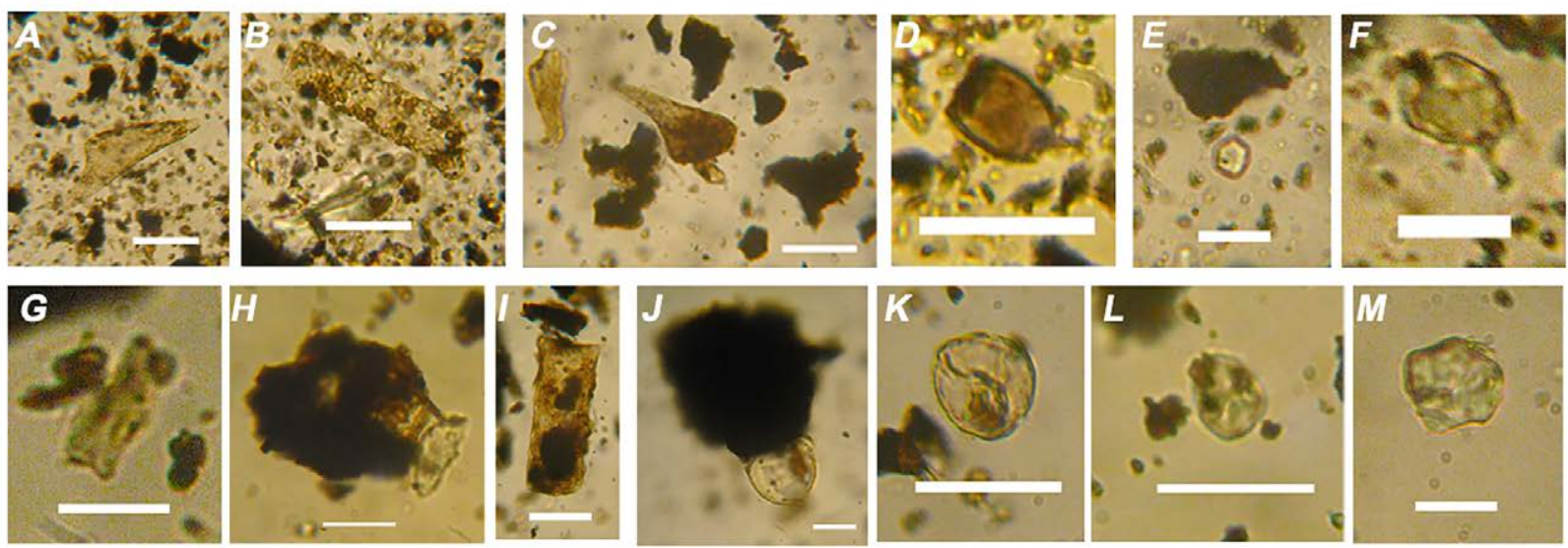

Figura 2. Microrrestos vegetales adheridos a la superficie de los tiestos de los sitios MB y RH. Arriba: muestras 2 y 2bis del tiesto RH C6-6- 13; $A-D$ ) fitolitos; $E-F)$ granos de almidón simples de Zea mays. Abajo: muestra 5 del tiesto MB2o; G-I) fitolitos; J) fragmento de hifa de hongo junto a materia orgánica; K) esporomorfo; L) grano de almidón simple Prosopis sp.; M) grano de almidón simple de Zea mays. Nota: Escala fotos A-D y G-K 20 $\mathrm{mm}$; escala fotos E, F, L y M $10 \mu \mathrm{m}$.

\section{Discusión y conclusiones}

La presencia de almidones de maíz en vasijas cerámicas de MB y RH y del microrresto de algarrobo en la muestra de MB indicaría que estas plantas fueron usadas por las poblaciones que habitaron diversos ambientes del norte de Mendoza entre aproximadamente los 2.000 y 1.000 años AP. La presencia de macrorrestos y los estudios isotópicos en huesos humanos permitieron proponer en trabajos previos que las plantas domésticas aparecieron en la región en torno a los ca. 2.000 años AP (Gambier, 2000; García, 1992; Gil et al., 2014a; Lagiglia, 2001; Roig, 1977). Existe evidencia temprana de macrorrestos de maíz en sitios de precordillera (Durán y García, 1989; García, 1988), destacando el sitio San Ignacio (valle de Potrerillos) que tiene una casa semisubterránea y dataciones entre los $1310 \pm 40$ años AP y los $1690 \pm 40$ años AP (Gasco et al., 2011). Por otra parte, el registro arqueológico de algarrobo se ha detectado en contextos precordilleranos, la más temprana en el sitio Agua de la Tinaja I, junto a maíz y otras plantas silvestres y cultivadas (Bárcena et al., 1985).

Este estudio es el primero en realizar análisis de contenidos a partir de la arqueobotánica en la región y el primero en registrar la presencia de microrrestos vegetales en los residuos de uso de las vasijas cerámicas. En este sentido, contribuye al conocimiento del consumo de vegetales entre las poblaciones tempranas del norte de Mendoza y también a la función que habría cumplido la cerámica en la subsistencia de los grupos que incorporaron cultígenos a su dieta. Planteamos preliminarmente que en el piedemonte del norte de Mendoza el binomio cerámica - plantas cultivadas habría ingresado a los contextos domésticos tempranamente y estaría relacionado, entre otros roles, con la explotación de alimentos con bajos rendimientos calóricos y mayores costos de procesamiento. Desde una perspectiva sistémica, la incorporación de la cerámica habría sido el resultado de la adaptación de las poblaciones al medio, ya que en la interacción de la cultura con el ambiente, la alfarería es un canal del flujo entre los humanos y los nutrientes necesarios para la subsistencia (Arnold, 1985). Este material posee ventajas tecnológicas respecto de otros (p. ej. cestería, piel, madera), ya que optimiza el flujo de sustancias nutritivas, facilitando la cocción de alimentos y permitiendo ampliar la ingesta de plantas que necesitan ser cocidas, haciéndolas digeribles y palatables, como el maíz (Arnold, 1985). Considerando los antecedentes y los contextos de hallazgo, se propone exploratoriamente que los microrrestos de maíz detectados en la superficie de las vasijas corresponderían a restos del procesamiento culinario de esta planta, aunque hay que tener en cuenta que los restos obtenidos de la muestra 5 de MB20 fueron 
obtenidos de la superficie externa y que no se registró presencia de daños producidos por prácticas culinarias (Babot, 2003, 2007) en los granos de almidón recuperados.

Las dataciones tempranas de la casa semi-subterránea (Rasgo 3) de MB, de ca. 2.000 años AP, constituyen una de las evidencias más tempranas del asentamiento humano en el piedemonte mendocino (Chiavazza et al., 2018). Desde esta perspectiva, los almidones de maíz y de algarrobo hallados en la muestra de la casa serían algunos de los registros más tempranos de ambas plantas en el piedemonte del COA. En esta muestra, los microrrestos fueron obtenidos de la superficie externa del fragmento, por lo cual no es posible identificar el origen de estos almidones, ya que podrían proceder tanto del salpicado del alimento cocido dentro de la vasija como del combustible usado en el fogón o del sedimento depositado en el área de procesamiento culinario.

La ocupación temprana de la casa semisubterránea de $\mathrm{MB}$, sumada a la evidencia de las mismas características y dataciones en Barrancas (Marsh, 2017), ambos ubicados en el piedemonte normendocino, permiten plantear que el proceso de intensificación económica propuesto para la precordillera del área —-desarrollado alrededor de ca. 1.500 años AP, con la incorporación de cultígenos y de casas semi-subterráneas (Cortegoso, 2006) - pudo desarrollarse tempranamente en las tierras bajas.

Respecto a la evidencia de RH, ubicado en las Pampas Altas de precordillera, la presencia de taxones de maíz en la muestra procedente de un contexto ubicado entre los 800 y 1.500 años AP, se corresponde con la evidencia de macrorrestos recuperada en otros sitios precordilleranos datados entre los 2.000 y 600 años AP (El Jagüelito, Agua de La Cueva sector norte y Cueva del Toro) (Durán y García, 1989; García, 1988; Sacchero y García, 1988). Esto se corresponde con la evidencia que indica que alrededor de los 1.000 años AP los picos de los valores isotópicos son altos y coinciden con anomalías positivas en la temperatura de verano (Gil et al., 2014a). En este sentido, el consumo de maíz en ambientes de altura daría cuenta de la relación entre los habitantes estacionales de los abrigos precordilleranos y las poblaciones ubicadas en los valles (Potrerillos y piedemonte) donde pudieron ubicarse las tierras de cultivo.

Este trabajo es una primera aproximación al análisis de los microrrestos vegetales recuperados en residuos de uso y consumo de fragmentos cerámicos del centro occidente argentino. Los resultados se restringen a escasos fragmentos y microrrestos, por lo cual las interpretaciones son limitadas y se deberá ampliar la muestra y analizar otros registros (macrorrestos y sedimentos) para discutir el procesamiento de plantas en contenedores cerámicos. Más allá de esto, entendemos que hay potencial en los materiales de la región, por lo cual, futuras investigaciones permitirán aportar al conocimiento de la alimentación de las poblaciones prehispánicas tempranas de la región y a las implicancias de la incorporación de la alfarería en la subsistencia.

\section{Agradecimientos}

Esta investigación se hizo con el financiamiento de la SECTyP, Universidad Nacional de Cuyo, Proyecto 06/G016 y del PICT-2013-019, FONCYT. Agradecemos el apoyo de: CONICET, Centro de Investigaciones Ruinas de San Francisco (Municipalidad de Mendoza) y todos los miembros que participaron en las labores de campaña y laboratorio. A Guillermina Elias por su asesoramiento en la traducción y a los evaluadores anónimos que contribuyeron a mejorar el manuscrito. 


\section{Q Referencias citadas}

"Abraham, E. (2000). La región andina argentina, Argentina. En E. Abraham y F. Rodríguez (Eds.), Recursos y Problemas Ambientales de la Zona Árida, Primera Parte, Provincias de Mendoza, San Juan y La Rioja (Tomo I) (pp. 7-14). Argentina: Programa de Cooperación para la Investigación, Junta de Gobierno de Andalucía, Universidades y Centros de Investigación de la Región Andina Argentina.

" Arnold, D. (1985). Ceramic Theory and Cultural Process. Cambridge: Cambridge University Press.

» Babot, M. del P. (2003). Starch grain damage as an indicator of food processing. En D. Hart y L. Wallis (Eds.), Phytolith and Starch Research in the Australian-Pacific-Asian Regions: the State of the Art (pp. 69-81). Canberra: Pandanus Books, Research School of Pacific and Asian Studies at the ANU.

» Babot, M. del P. (2007). Granos de almidón en contextos arqueológicos: posibilidades y perspectivas a partir de casos del Noroeste argentino. En B. Marconetto, P. Babot y N. Oliszewski (Eds.), Paleoetnobotánica del Cono Sur: Estudios de Casos y Propuestas Metodológicas (pp. 95-125). Córdoba: Museo de Antropología.

» Bárcena, J. (2001). Prehistoria del centro oeste argentino. En E. Berberián y A. Nielsen (Eds.), Historia Argentina Prehispánica (Tomo 2) (pp. 561-634). Córdoba: Editorial Brujas.

" Bárcena, J., Roig, F. y Roig, V. (1985). Aportes arqueo-fito-zoológicos para la prehistoria del N.O. de la provincia de Mendoza: la excavación de Agua de la Tinaja I. Trabajos de Prehistoria, 42, 311-363.

»Chiavazza, H. (1995). Estudios arqueológicos en el sitio «Rincón de Los Helados» («RH»). Ocupación multicomponente en noreste de Pampa de Canota - Departamento de Las Heras, Provincia de Mendoza, República Argentina. (Tesis de Licenciatura inédita), Universidad Nacional de Cuyo, Argentina.

»Chiavazza, H. (2015). Pescadores y horticultores ceramistas del valle de Mendoza. En R. Bárcena (Ed.), Xama. Serie Monografías. Arqueología y Etnohistoria del Centro Oeste Argentino. Aportes desde la V Jornadas Arqueológicas Cuyanas 5 (pp. 45-62). Mendoza: Zeta Editores.

»Chiavazza, H. y Mafferra, L. (2007). Estado de las investigaciones arqueobotánicas en Mendoza y sus implicancias en la arqueología histórica. Revista de Arqueología Histórica Argentina y Latinoamericana, 1, 127-154.

»Chiavazza, H., Prieto-Olavarría, C., Puebla, L., Quiroga, M., López, M., Mafferra, L., Castillo, L. y Anzorena, J. (2018). Ocupaciones alfareras tempranas en el valle de Mendoza (Centro Oeste Argentino). Intensificación económica durante el Holoceno Tardío. Manuscrito inédito.

"Cortegoso, V. (2006). Comunidades agrícolas en el Valle de Potrerillos (NO de Mendoza) durante el Holoceno tardío: organización de la tecnología y vivienda. Intersecciones en Antropología, 7, 77-94.

"Durán, V. y García, C. (1989). Ocupaciones agroalfareras en el sitio Agua de La Cueva Sector Norte (N.O. de Mendoza). Revista de Estudios Regionales CEIDER, 3, 29-64.

" Falabella, F. y Stehberg, R. (1989). Los inicios del desarrollo agrícola y alfarero: zona central (300 a. C. a 900 d. C.). En J. Hidalgo, V. Schiappacasse, H. Niemeyer, C. Aldunate del Solar e I. Solimano (Eds.), Prehistoria (pp. 295-311). Santiago: Editorial Andrés Bello. 
» Gambier, M. (2000). Prehistoria de San Juan. San Juan: Ansilta.

»García, A. (1988). Arqueología de la Cueva del Toro (Mendoza-Argentina). Revista de Estudios Regionales CEIDER, 1, 17-71.

»García, A. (1992). Hacia un ordenamiento preliminar de las ocupaciones prehistóricas agrícolas precerámicas y agroalfareras en el NO de Mendoza. Revista de Estudios Regionales CEIDER, 10, 7-34.

» Gasco, A. V., Marsh. E., Frigolé, C., Castro, S., Privitera, C., Moyano, R. y Yebra, L. (2011). Actividades domésticas durante los siglos III-VIII d.C. en el valle de Potrerillos (San Ignacio - Mendoza): un acercamiento desde la osteometría y la tecnología cerámica y lítica. Revista del Museo de Antropología, 4, 145-16o.

» Gil. A. (2006). Arqueología de La Payunia. El Poblamiento Humano en las Márgenes de la Agricultura. Oxford: BAR Internacional Series 1477.

» Gil, A., Villalba, R., Ugan, A., Cortegoso, V., Neme, G., Michieli C. T., Novellino, P. y Durán, V. (2014a). Isotopic evidence on human bone for declining maize consumption during the Little Ice Age in central western Argentina. Journal of Archaeological Science, 49, 213-227.

» Gil, A., Giardina, M., Neme, G. y Ugan, A. (2014b). Demografía humana e incorporación de cultígenos en el centro occidente argentino: explorando tendencias en las fechas radiocarbónicas. Revista Española de Antropología Americana, 44(2), 523-553.

» Gil, A., Neme, G. y Tykot, R. (2010). Isótopos estables y consumo de maíz en el Centro Occidente Argentino: tendencias temporales y espaciales. Chungara. Revista de Antropología Chilena, 42(2), 497-513.

» Gil A., Neme, G., Tykot, R., Novellino, P., Cortegoso, V. y Durán, V. (2008). Stable isotope and maize consumption in Central Western Argentina. International Journal of Osteoarchaeology, 19, 215-236.

» Gil, A., Tykot. R., Neme, G. y Shelnut, N. (2006). Maize on the frontier. Isotopic and macrobotanical data from Central West Argentina. En J. Staller, R. Tykot y B. Benz (Eds.), Histories of Maize (pp. 199-214). Burlington: Academic Press.

» Giovannetti, M., Lema, V., Bartoli, C. y Capparelli, A. (2008). Starch grain characterization of Prosopis chilensis (Mol.) Stuntz and P. flexuosa DC, and the analysis of their archaeological remains in Andean South America. Journal of Archaeological Science, 35, 2973-2985.

»Korstanje, M. A. y Babot, M. del P. (2007). Microfossils characterization from south Andean economic plants. En M. Madella y D. Zurro (Eds.), Plants, People and Places: Recent Studies in Phytolith Analysis (pp. 41-72). Cambridge: Oxbow Books.

» Lagiglia, H. (1980). El proceso de agriculturización del sur de Cuyo: la cultura del Atuel II. Actas del V Congreso Nacional de Arqueología Argentina (Volumen I) (pp. 231-252). San Juan: Universidad Nacional de San Juan, Facultad de Filosofía, Humanidades y Artes, Instituto de Investigaciones Arqueológicas y Museo.

» Lagiglia, H. (2001). Los orígenes de la agricultura en la Argentina. En E. Berberián y A. Nielsen (Eds.), Historia Argentina Prehispánica (Tomo 1) (pp. 41-81). Córdoba: Editorial Brujas.

» Mafferra, L. (2010). Problemática en torno al registro arqueobotánico de Mendoza. En R. Bárcena y H. Chiavazza (Eds.), Arqueología Argentina en el Bicentenario de la Revolución de Mayo Año (Tomo V) (pp. 2083-2088). Mendoza: FFyL, UNCuyo, INCIHUSA-CONICET.

» Marsh, E. (2017). La fecha de la cerámica más temprana en los Andes sur. Una perspectiva macrorregional mediante modelos bayesianos. Revista del Museo de Antropología, Suplemento Especial 1, 83-94. 
» Musaubach, M. G. (2014). Microrrestos vegetales en contenedores cerámicos. Análisis arqueobotánicos en un contexto de cazadores recolectores de pampa occidental (Argentina). En C. Belmar y V. Lema (Eds.), Avances y Desafíos Metodológicos en Arqueobotánica: Miradas Consensuadas y Diálogos Compartidos desde Sudamérica (pp. 278-300). Santiago de Chile: Facultad de Patrimonio Cultural y Educación. Universidad SEK.

» Musaubach, M. G. (2017). Microrrestos vegetales en residuos arqueológicos. Propuesta Metodológica para su estudio arqueobotánico. Relaciones de la Sociedad Argentina de Antropología, XLII (2), 379-388.

» Musaubach, M. G. y Berón, M. (2017). Food residues as indicators of processed plants in hunter-gatherers' pottery from La Pampa (Argentina). Vegetation History and Archaeobotany, 26, 111-123.

» Musaubach M. G., Plos, A., Babot M. del P. (2013). Differentiation of archaeological maize (Zea mays L.) from native wild grasses based on starch grain morphology. Cases from the Central Pampas of Argentina. Journal of Archaeological Science, 40, 1186-1193.

»Neme, G. (2007). Cazadores-recolectores de Altura en los Andes Meridionales: el Alto Valle del Río Atuel. Oxford: BAR International Series 1591.

»Neme. G. y Gil, A. (2008). Biogeografía humana en los andes meridionales: tendencias arqueológicas en el sur de Mendoza. Chungara. Revista de Antropología Chilena, 40(1), 5-18.

»Ots, M. J., Oliszewski, N. y García Llorca, J. (2011). Estrategias alimentarias y de subsistencia prehispánica en el centro-oeste de Mendoza: consumo y descarte en el sitio arqueológico Agua Amarga. Revista del Museo de Antropología, 4, 65-80.

»Piperno, D. (2006). The origins of plant cultivation and domestication in the neotropics: a Behavioral Ecological Perspective. En Kennett, D. y Winterhalder, B. (Eds.), Foraging Theory and the Transition to Agriculture (pp. 137-166). Berkeley: University of California Press.

»Prieto, M. R. ([1983] 2000). Formación y consolidación de una sociedad en un área marginal del Reino de Chile: la Provincia de Cuyo en el siglo XVII. Anales de Arqueología y Etnología, 52-53, 11-366.

» Roig, F. A., (1977). Frutos y semillas arqueológicos de Calingasta, San Juan. En M. Gambier (Ed.), La cultura de Ansilta (pp. 216-250). San Juan: Instituto de Investigaciones Arqueológicas y Museo, UNSJ.

» Roig, F., Martínez Carretero, E. y Méndez, E. (2000). Mapa de vegetación de la provincia de Mendoza. En M. E. Abraham y F. Rodríguez (Eds.), Argentina, Recursos y Problemas Ambientales de la Zona Árida (1ra parte II). Argentina: Programa de Cooperación para la Investigación, Junta de Gobierno de Andalucía, Universidades y Centros de Investigación de la Región Andina Argentina.

» Rusconi, C. (1961). Poblaciones Pre y Post hispánicas de Mendoza (Tomo I) Etnografía. Mendoza: Edición oficial.

»Sacchero, P. y García, A. (1988). Noticia sobre la ocupación agroalfarera de la Cueva El Jagüelito. Informe preliminar. Revista de Estudios Regionales CEIDER, 2, 7-41.

» Skibo, J. (2015). Pottery use-alteration analysis. En J. Marreiros, J. Gibaja y N. Ferreira (Eds.), Use-Wear and Residue Analysis in Archaeology, Manuals in Archaeological Method, Theory and Technique (pp. 189-198). Suiza: Springer International Publishing.

»Zucol, A., Brea, M. y Passeggi, E. (2008). Los estudios fitolíticos en América del Sur, una visión retrospectiva. En A. Korstanje y M. del P. Babot (Eds.), Matices Interdisciplinarios en Estudios Fitolíticos y de Otros Microfósiles (pp. 3-21). Oxford: BAR International Series $\mathrm{S} 1870$. 